\title{
Conflicts, military medicine and war casualties in international Orthopaedics
}

\author{
Marius M. Scarlat ${ }^{1} \cdot$ Andrew Quaile ${ }^{2} \cdot$ James P. Waddell $^{3}$
}

Published online: 13 December 2019

(C) SICOT aisbl 2019

The recent SICOT world orthopaedic surgery and traumatology congress in Oman was a great meeting with thousands of attendees, brilliant talks, educational lectures, instructional courses and seminars, symposia and many free papers presented by speakers from five continents. The International Council of the SICOT is formed by orthopaedic surgeons who represent their respective countries. At the Annual Assembly of the Council some countries were missing. A few colleagues were unable to attend for specific reasons that are not related with scientific or academic issues. Some colleagues live in places that are in state of war or have no freedom to circulate. Some others belong or work in places where the airports or roads were recently destroyed. Finally, some colleagues were unable to attend due to restrictions of circulation or visa delivery in their local or regional areas. However, the art of Orthopaedic Surgery is a part of our society, everywhere on the planet our colleagues are treating wounded people, military or civilian from every population group of, including their enemies. During difficult times, combat, terror attacks or war our colleagues manage specific casualties, terrible and disabling limb wounds, catastrophic trauma, partial or total limb loss, chemical, thermic burns, penetrating injuries from high-velocity weapons and many other conditions. During these particular periods of time civilians may be "collateral damage" and often they represent more cases than the military personnel. Trauma was considered for many years as the "poor child" of orthopaedics and scheduled routine surgery was the main option in every general

Marius M. Scarlat

1 Orthopaedic Department, Clinique Chirurgicale St Michel, Groupe ELSAN, Toulon, France

2 Spineworks; Hampshire Clinic, Basingstoke, Hampshire, UK

3 From the Orthopaedic Department, St Michael Hospital, Toronto, ON, Canada hospital except in dedicated trauma centres. The picture changes obviously in time of war or after natural catastrophies when mass causalities become a priority and every orthopaedic surgeon will eventually become a trauma care provider.

International Orthopaedics publishes every year papers related to war traumatology and secondary treatment of sequellae. This chapter was started during Mr. Maurice Hinsenkamp presidency of SICOT and was supported by many countries and institutions, including military hospitals from different countries and "Médecins sans Frontières" a powerful International organization started in France and dedicated to helping people in difficult situations, including war, natural disasters and terror attacks on civilians.

The December issue of the Journal published the "war and catastrophy" chapter and included four relevant papers that present different conditions of the osteo-articular system after combat trauma and the different methods of management.

The treatment of war wounds is based on a sequential surgical strategy, which frequently faces therapeutic failures, which could compromise or complicate the final functional result. The study published by the French specialty centres [1] is a valuable piece of research that identifies potential risk factors and provides solutions for the management of those specific cases.

A paper authored by specialists working with "Medecins sans Frontières" discusses tibial bone gaps after war injuries [2]. Tibial bone loss is common in war and can be managed by different types of surgery, including compression osteosynthesis, bone graft, tibialisation of fibula, bone transportation, and free flaps. The paper describes the experience of one humanitarian hospital and identifies key factors affecting the patient outcomes providing an expert opinion for dealing with such severe conditions. The study is based on a series of two hundred cases with over one hundred cases complicated with tibial bone defects, followed for over four years and therefore it is a valuable resource. The bone gap size was not correlated with the outcomes, an unexpected finding. This can be related to the vascularity according to the authors. 
The paper authored by Alhammoud, Maaz and colleagues is based on observations after treating nine-hundred and fiftyfive patients with open long bone fractures (femur, tibia, humerus) operated upon and reviewed at a field hospital in Aleppo, Syria, from 2011 to 2016. Different types of uniplanar and some multiplanar external fixators were used as primary and definitive fixation devices until bone union was achieved. The union rates and infections were reported in association with age, gender, Gustilo/Anderson classification, type of fixator, and presence of neurovascular injuries. This paper is important and provides solutions related also to the interference with infection or other possible complications, pointing out that the external fixation could be used as unique device until final consolidation occurs, in selected cases or in special conditions. [3]

The paper of Karami and colleagues comes from Beirut, Lebanon a region that faces frequent conflicts and war injuries of the distal lower extremity including large composite defects involving bone and soft tissues. The authors experience on fifteen cases treated in 2015 and 2016. All defects were reconstructed using a single barrel free fibula osteo- $( \pm$ myo)cutaneous flap. With a follow-up of over four-hundred days and an average bone-healing time of nine months, no infection and three complications managed, this paper is a good expert opinion on the management of these defects so difficult to heal with conventional surgery. They recommend careful planning and impeccable technical realization. [4]
These valuable resources are useful for general orthopaedic surgeons, specialists in microsurgery and infection and also for the young colleagues who are educated to become orthopaedic experts but could be appealed to become trauma or emergency specialists in difficult times.

\section{References}

1. Grosset A, Pfister G, de L'Escalopier N, Plang S, Russo A-P, Murison JC, Mathieu L, Rigal S (2019) Risk factors and failures in the management of limb injuries in combat casualties. Int Orthop (SICOT) 43(12):2671-2680. https://doi.org/10.1007/s00264-01904329-7

2. Fakhri RM, Herard P, Liswi MI, Boulart AL, Al Ani AMK (2019) Decision-making algorithm for sequential treatment of diaphyseal bone gaps in war-wounded patients in the Middle East. Int Orthop (SICOT) 43(12):2653-2659. https://doi.org/10.1007/s00264-01904317-x

3. Alhammoud A, Maaz B, Alhaneedi GA, Alnouri M (2019) External fixation for primary and definitive management of open long bone fractures: the Syrian war experience. Int Orthop (SICOT) 43(12): 2661-2670. https://doi.org/10.1007/s00264-019-04314-0

4. Karami RA, Ghieh FM, Chalhoub RS, Saghieh SS, Lakkis SA, Ibrahim AE (2019) Reconstruction of composite leg defects postwar injury. Int Orthop (SICOT) 43(12):2681-2690. https://doi.org/ 10.1007/s00264-019-04423-w

Publisher's note Springer Nature remains neutral with regard to jurisdictional claims in published maps and institutional affiliations. 